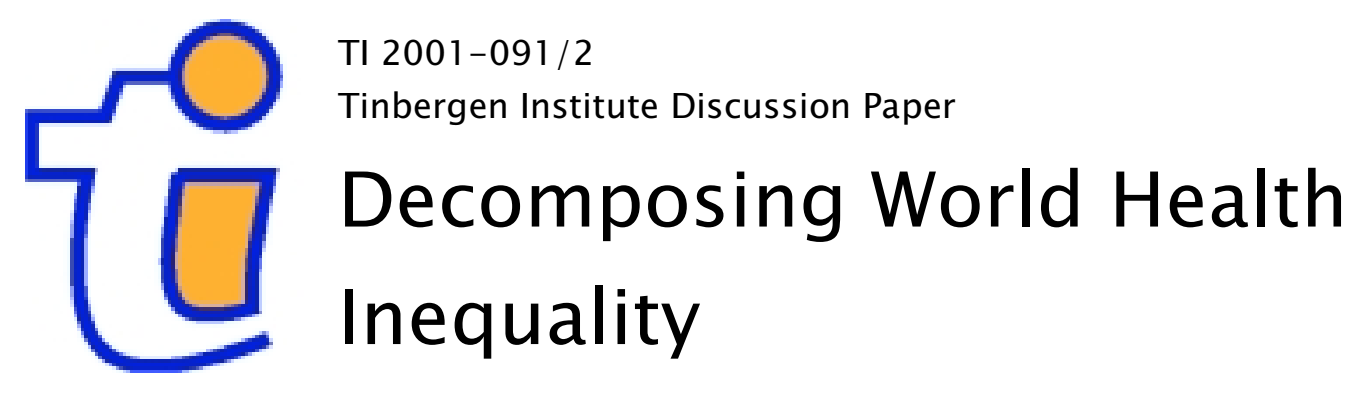

Menno Pradhan 1,2,3

David E. Sahn

Stephen D. Younger 4

1 World Bank, 2 Economic and Social Institute, Faculty of Economics and Business Administration, Vrije Universiteit Amsterdam, 3 Tinbergen Institute, 4 Cornell University 
Tinbergen Institute

The Tinbergen Institute is the institute for economic research of the Erasmus Universiteit Rotterdam, Universiteit van Amsterdam and

Vrije Universiteit Amsterdam.

Tinbergen I nstitute Amsterdam

Keizersgracht 482

1017 EG Amsterdam

The Netherlands

Tel.: +31.(0)20.5513500

Fax: $\quad+31 .(0) 20.5513555$

Tinbergen Institute Rotterdam

Burg. Oudlaan 50

3062 PA Rotterdam

The Netherlands

Tel.: $\quad+31 .(0) 10.4088900$

Fax: $\quad+31 .(0) 10.4089031$

Most TI discussion papers can be downloaded at

http://www.tinbergen.nl 


\title{
DECOMPOSING WORLD HEALTH INEQUALITY
}

\author{
Menno Pradhan \\ World Bank \\ David E. Sahn \\ Cornell University \\ Stephen D. Younger \\ Cornell University
}

September, 2001 


\begin{abstract}
This study explores global inequality in health status, and decomposes it into within- and between-country inequality. We rely on standardized height indicators as our health indicator since they avoid the measurement pitfalls of more traditional measures of health such as morbidity, mortality and life expectancy. They also avoid measurement problems associated with using incomes across time or place to compare welfare. Our calculation of world height inequality indicates that in contrast with similar research on income inequality, within-country variation is the source of most inequality, rather than the differences between countries.
\end{abstract}

Keywords: health; inequality 


\section{Introduction}

This study documents global inequalities in health in a novel way. Rather than consider the health of people across the income distribution or some other measure of social stratification, we examine inequality in health status in and of itself. ${ }^{1}$ Our domain of inquiry is to explore the inequality in health status. We are motivated by the fact that health is an important indicator of well-being. Just as measuring the dispersion of income is of interest, so too are statements about inequality in health status. Although the properties of health inequality differ in many important respects from the widely understood measures of income inequality, the measure of health inequality that we propose has some useful and convenient properties that make it particularly attractive and interesting. In addition, while our focus is on measurement, our work has potentially important policy implications. In particular, we will show how the decomposition of inequality in health status may have implications for resource allocation and program targeting.

Most of the literature on health inequality explores how health differs across various socio-economic dimensions. The positive correlation, or "gradient," between health and socioeconomic status has led researchers to focus on income related inequalities in health status and access, or on the importance of relative income or social position as a determinant of health (e.g., Wagstaff et al.,1991; van Doorslaer et al., 1997; Mackenbach and Kunst, 1997; Gwatkin 1999, 2000; Brockerhoff and Hewett, 2000). ${ }^{2}$ Much of this literature is thus grounded in a welfare framework where the fundamental measure of well-being is income, ${ }^{3}$ and differences in health outcomes are analyzed across the income (or expenditure) distribution. There are also papers that study how health varies across other socioeconomic dimensions such as ethnicity, geographical location, and gender. The problems of poor health status and health inequality are seen as a result of income inequality, or an underlying social process that contributes to inequality among socioeconomic groups in the population. ${ }^{4}$

Empirically, studies often find a positive correlation between health and many indicators of socioeconomic status or various measures of social stratification. Nevertheless, the correlation between health and these other social indicators, including income and expenditures, is sufficiently weak that in any given sample, income and the measures of social stratification usually predict only a small portion of the variation in health status. This applies to a variety of health measures, including the standardized heights of children that we employ in this paper. Many other factors are important in explaining health status. A wide variety of social and economic circumstances and

\footnotetext{
${ }^{1}$ Gakidou, Murray and Frenk (2000) are similarly motivated in their effort to examine disparities in health status.

${ }^{2}$ There is also a body of research that examines the inequality of access to and use of health services by economic status. See, for example, Sahn and Younger (2000).

${ }^{3}$ In the case of gender, it may be that what drives inequities between men and women is not earnings or income per se, but control over how that income is allocated and spent. See, for example, Haddad, Hoddinott and Alderman (1997).

${ }^{4}$ Murray, Gakidou and Frenk (1999) point out that the magnitude of health inequality is conditioned by the critical choice of what variable is used to disaggregate the population into social groups.
} 
behaviors matter, including: the psychological state of the primary care-giver, weaning and other feeding practices, the social norms and behaviors that govern sexual transmission of diseases, and the natural occurrence of trace minerals and vitamins available in soils and foods. Community factors often matter, too. The availability and quality of the health care system and related public health measures such as water and sanitation, vaccination coverage, etc., have all been shown to be of equal or greater importance in determining child health than incomes. ${ }^{5}$ Even if these factors are positively correlated with incomes, or some other socioeconomic dimension, they have independent and important effects on health. By focusing solely on income related inequality in health, one therefore runs the risk of ignoring a large fraction of health inequalities, namely those that cannot be explained by income. By implication, reducing income inequality will not necessarily be an effective way of dealing with inequality in health, since the gradient fails to capture the fact that a wide range of unobservable factors beyond income influence health. This is especially the case because income distributions have a long right tail.

Therefore, while some have argued that the domain of interest should be focused on health inequalities that are correlated with other socioeconomic inequalities (e.g., Wagstaff et al., 1991), we are motivated by the suggestion of Deaton (2001) that health inequality is intrinsically important to the extent that it is meaningful to state that person $\mathrm{A}$ is healthier than person $\mathrm{B}$, just as it is with income. Put another way, consider two populations, $\mathrm{A}$ and $\mathrm{B}$, with equal levels of average health and equal levels of health inequality. However, assume that in population $\mathrm{A}$, there is a strong correlation between health and income, and in B, just the opposite. We would certainly not want to adopt the view that health inequality in population $\mathrm{A}$ is a more serious public policy problem, owing to the stronger correlation with income (or some other measure of social stratification). To the extent that we can identify a cardinal measure of health inequality, which we do in this paper, comparisons of distributions of health are meaningful, regardless of whether health inequality is correlated with welfare measured along other income related dimensions (e.g., Murray, Gakidou and Frenk 1999).

Thus, in this paper we focus on inequalities in child health status, not the correlations between health status and other socioeconomic indicators, or the "gradient," as it is commonly referred to. Perhaps the most simple way to distinguish what we do in this paper from the traditional approach is that our focus involves ordering individual well-being by health status or health condition, not income levels, and describing the inequality in health status across this health ordering.

\subsection{Why Health Inequality?}

A number of World Health Organization (WHO) policy statements and papers strongly articulate the need to reduce the differences in health status between countries and between socioeconomic groups within countries (e.g., WHO 1985, 1986; Whitehead,

\footnotetext{
${ }^{5}$ See, for example, Haughton (1997), Skoufias (1998), Sahn and Alderman (1997), Thomas, Lavy and Strauss (1996).
} 
2000). These calls beg the fundamental question as to why health inequality is of interest, as does our decision to focus on health inequality in and of itself. A number of considerations motivate this interest. First, Sen $(1979,1985,1987)$ argues that the notion of poverty is inadequately captured by income or expenditure. Poverty is the deprivation of basic capabilities, or the failure of certain basic functionings, not just low levels of income. Low incomes are only instrumentally significant, while deprivation of capabilities, such as poor health, are intrinsically important. Health, literacy, and so forth, are more direct measures of capability deprivation, or poverty, than income or expenditures. And to the extent that measures of health are appropriate arguments in the social welfare function, there are legitimate reasons to be concerned about health inequality directly.

Second, health inequality is more likely to reflect some notion of absolute deprivation in the population than does income inequality. This results from the fact that in the case of incomes, it is possible, and in fact often the case, that an increase in inequality is caused by a lengthening of the right-hand tail of the distribution. In addition, observed increases in income inequality can be offset by and increases in mean incomes, implying greater social welfare despite worsening inequality. In health - unlike incomes - there is a natural limit to improvements so that the distribution of health has no long right-hand tail. Worsening health inequality is therefore more likely to be caused by greater dispersion in the left-hand tail, i.e., by unhealthy people becoming more so. So it is more likely that health inequality is bad, at least in the context of social welfare functions that put more weight on the welfare of the poor.

A third argument for focusing on health inequality derives from the assertion of Wilkinson $(1996,1997)$ that lack of social cohesion, and other disparities in socioeconomic circumstances, including health status (as well as other considerations such as security), is a health risk. This risk goes beyond the correlation between low levels of income and low level of health. Wilkinson's case rests on what he refers to as the "neuroendocrine" pathways through which psychosocial risk factors link health to the inequality in socioeconomic circumstances. That is, psychosocial effects of relative deprivation, as might be measured by inequality of health status, in and of itself, is a risk factor for poor health.

Finally, there is a practical reason for focusing on inequality in health, rather than the gradients. It is often difficult to compare incomes and socioeconomic correlates of health across time or places. Constructing income and expenditure measures is complex and even minor deviations in survey design can influence them (e.g., Pradhan, 2000; Scott and Amenuvegbe, 1990). Furthermore, there is the problem of converting nominal incomes into comparable units. For inter-temporal welfare comparisons, this requires appropriate price deflators. Cross-country welfare comparisons require accurate purchasing power parity indices. High-quality indices of both types are scarce for poor countries. There is also the difficulty of defining comparable socioeconomic groups, which in fact, may have different compositions in different countries. For example, making urban vs. rural, or male- vs. female-headed household comparisons across 
countries may not be very meaningful if the definition of these categories and their determinants differ.

In contrast, many measures of health status, and particularly anthropometrics, are easily comparable across time and location. They are not plagued by the problems of survey design, comparability of nominal incomes, and socioeconomic definitions that affect incomes and expenditures. So, we are better able to make inter-temporal and intercountry comparisons when focusing on an objective health outcome indicator, rather than trying to define comparable income levels of socioeconomic groups.

While our primary concern in this paper is methodological, we do uncover an especially interesting policy-relevant finding: the extent to which global health inequality is a result of intra-country versus inter-country variation in health status. Specifically, we describe global health inequality of pre-school age children, and decompose it into the contribution of within- and between-country inequality. As a first attempt to deal with health inequality in this way, the objective of this paper is modest in so far as none of the work is explanatory, merely descriptive. Nonetheless, the results give a sense of how serious health inequality is in the world, and the decomposition indicates the relative importance of intra- or international inequalities for policymakers.

The remainder of this paper is organized as follows. First, we discuss in greater detail how to construct and standardize a decomposable health inequality measure using children's height. This is followed by a discussion of the data we employ. We next present the results of our decomposition analysis. This is followed by some concluding remarks, including how our results compare to similar exercises that examine global income inequality.

\section{Methods for defining and decomposing health inequality}

\subsection{Choice of health indicator}

There are numerous problems inherent in measuring health, and therefore in describing health inequality in a meaningful way. The most obvious candidates for measuring inequality in health are those indicators most often used to define health status: mortality, morbidity, and life expectancy. All are characterized by serious measurement problems that have impeded efforts to make statements about interpersonal variability of health status. For example, it is almost impossible to arrive at a reasonable expectation for an individual's life expectancy, despite that such a statistic is meaningful for populations. The life tables used to calculate life expectancy are based on data collected at a given point in time, but that time does not correspond to the future experiences of those presently alive (e.g., Deaton, 1999). Similarly, the use of related

indicators such as health risk, which are based on probabilities of death and incidence and remission of non-fatal health outcomes, cannot be measured at the individual level. Instead, approximations of health risk, as a function of age, must be made based on 
tenuous and incomplete information. ${ }^{6}$ Similarly, the probability that an individual will die based on mortality models is another potential measure of health status. But econometric mortality models suffer from poor predictive capability, in large measure because mortality remains a sufficiently rare stochastic event that its modeling remains problematic.

Morbidity is yet another obvious candidate for measuring inter-personal differences in health, and it is observable. However, the mismeasurement of selfreported illness is well documented for both specific ailments and general health status. One prominent manifestation of the bias in self-reported illness is the nearly universal finding from surveys conducted in developing countries that the rich are more likely to be ill than the poor. While factors such as greater health awareness among the rich and the poor's tendency to disregard illnesses to which they are accustomed may explain this finding, such bias in reporting precludes characterizing the distribution of health using self-reported morbidity.

Given these difficulties, in this paper we will use growth of children - recumbent length or height - as the basis for making statements about the distribution of health in the population. Height of children has a number of properties that make it appropriate for our purpose. Most important, impaired linear growth, or stunting, reflects long-term poor health and chronic malnutrition. Thus, using height data to arrive at statements about the percent of a population that is chronically malnourished or in poor health, is well established in the literature.

Drawing conclusions about the degree of health inequality based on height data also has a series of desirable properties. A first advantageous property of height as an indicator over which we can assess inequality, which contrasts with the use of income, revolves around the facts that height has natural limits, and its empirical distribution in a healthy population is normal. As discussed earlier, when height inequality occurs, it is largely due to a leftward skew, a statistical property that we believe makes the height variable attractive. Second, by relying on height, as contrasted with other measures of health, we avoid the risk that a Pareto improvement is brought about by new health information or practices, despite that health inequality has worsened. This could occur, for example, if some new technology reduced coronary heart disease, thus helping the wealthy, but having little benefit for the poor. Thus, health inequality would increase, but a Pare to improvement in public health would occur. ${ }^{8}$ For height, almost all populations will have a significant share of children who are sufficiently well-off that that they attain their full genetic potential height. In such populations, reductions in health inequality are almost surely correlated with improvements in overall welfare.

\footnotetext{
${ }^{6}$ See Gakidou, Murray and Frenk (2000) who estimate individual health risks by age and summarize them in a health survivorship function.

${ }^{7}$ WHO (1983).

${ }^{8}$ The exception is if there are countries where the whole population is below their potential, it is possible that an increase in inequality is joined by an increase in average height.
} 
And third, there are pragmatic reasons for relying on height as a measure of health inequality that go beyond the properties discussed above. Surveys are widely available from a large number of countries that cover the vast majority of the world's population. And unlike the measurement of income, morbidity, and so forth, there is little variability in the measurement technique, which limits the potential for non-sampling errors. In addition, height measurement is comparable across regions, countries and time, so that we do not have to worry about the comparability of monetary variables or socioeconomic concepts such as household headship, labor market status, etc.

\subsection{Dealing with natural variation}

Despite these desirable characteristics of using height as a measure of inequality, we must deal with the fact that using heights to measure inequality is complicated by the fact that in a healthy population, there is genetic variation in the height potential of individuals (see Carr, 1988). As such, there will always be variations in child heights, standardized for age and gender, even in a healthy population with complete health equality. To respond to this concern about the heterogeneity in heights of healthy individuals, we use measurements from a healthy population to establish the range of genetically determined variation in heights of children. We then assess the extent to which the distribution of heights in our sample, conditional on gender and age, differs from the healthy reference population to quantify health inequality. In this analysis, we take the National Center for Health Statistics reference population as representative of the healthy population. According to the World Health Organization, this population is of globally representative healthy, well- nourished children (see WHO 1983) thus providing the basis for our assumption that the distribution of standardized heights in that population represents only genetic inequality. For our purposes, then, health inequality in the NCHS population is set to be zero by definition. Inequality in all other populations is then established relative to inequality in the reference population.

Our ability to adjust for "natural" variation when using anthropometric measures contrasts with income and many other measures of socio-economic well-being, where both non-sampling errors and variable needs will lead to an underlying variance in the measure, even in the absence of welfare inequality. Unlike height, however, nonsampling error and variable needs make it all but impossible to assess the underlying variation of other welfare measures. Certainly, such variation is almost always ignored in traditional analysis of income inequality.

\subsection{Decomposition}

Our analysis of health inequality is based on the height of children up to 59 months old. The variance of height naturally increases as children get older. Because the age pyramid varies by country, and because we wish to give variations in each age group equal importance in the analysis, we use a transformed height measure for our inequality analysis. The transformed height measure is standardized using a fixed age/sex reference group, which in our case, is girls at 24 months of age. The actual height of children in the sample is transformed to a standardized height using the distribution of heights, by age 
and sex, of the NCHS reference population. The standardized height measure is constructed such that the position, in terms of percentiles, is the same for actual height in the actual age/sex group and the transformed height in the reference group NCHS distribution. More specifically,

$$
H=F_{\bar{a}, \bar{g}}^{-1}\left(F_{a, g}(h)\right)
$$

where $\mathrm{F}$ is the distribution function of heights in the NCHS population for age/sex group defined by a (age) and $g$ (gender). $h$ is the actual height.

We use the Theil entropy measure as our measure of inequality because it is decomposable by groups. For a given country $k$, the Theil index is defined by

$$
T(k)=\frac{1}{N} \sum \ln \left(\frac{\mu}{H_{i}}\right)
$$

Inequality in health is measured by the country's inequality minus the natural inequality, which prevails in the NCHS reference population of healthy children:

$$
I(k)=T(k)-T(N C H S)
$$

Like the Theil entropy measure, the index can be decomposed to between-group and within-group inequality. Let the universe consist of $\mathrm{K}$ countries, including some countries with no stunting and thus no health inequality. World inequality can now be decomposed according to:

$$
I(\text { world })=T(\text { world })-T(N C H S)=\sum_{k=1}^{K} \frac{N_{k}}{N}[I(k)]+\frac{1}{N} \sum_{k=1}^{K} N_{k} \ln \left(\frac{\mu}{\mu_{k}}\right)
$$

where $\mu$ is the average height for the entire sample, $\mu_{k}$.is average height for country $K, N$ is the entire sample size, and $N_{k}$ is the sample size in country $K$. The latter term defines between-country inequality as the inequality at country means, while the first term sums all within-country inequality. Note that there is no natural level of between-group inequality. In a perfectly healthy world the between-country inequality term would be zero.

The arbitrary choice in this whole procedure is the choice of the reference group (to transform the heights). As children get older, genetic variation in heights increases, so we can influence our inequality measure by our choice of reference age and gender (i.e., the younger the reference group, the less unequal the distribution of heights). This will also hold for the difference in equality T(world)-T(NCHS). In order to counter that effect, we divide by the Theil inequality in the reference group T(NCHS) as follows: 


$$
I^{*}(\text { world })=\frac{I(\text { world })}{T(N C H S)}=\sum_{k=1}^{K} \frac{N_{k}}{K}\left[I^{*}(k)\right]+\frac{\frac{1}{N} \sum_{i=1}^{3} N_{k} \ln \left(\frac{\mu}{\mu_{k}}\right)}{T(N C H S)}
$$

So if we choose a younger reference group, the difference will be smaller, but we will also be dividing by a smaller number.

\section{Data}

The data used in our analysis are primarily from the Demographic and Health Surveys (DHS), a project that has collected representative data on child health, fertility, contraceptive use, and related demographic data throughout the developing countries for the past 15 years. 9 The data are all collected in a comparable fashion, following a set of detailed and common procedures. Beyond our reliance on the DHS, we use Living Standards Measurement Survey ${ }^{10}$ data from Ecuador, Romania, Russia and South Africa, as well as data from the Ministry of Health in the case of China. All of these surveys were designed to be nationally representative.

In the case of OECD countries, we make the assumption that there is no malnutrition. While this is no doubt optimistic, it is also likely that the incidence levels are so small that our results are not sensitive to this assumption. In combination with the data from the developing countries, the coverage of the world's population in our analysis is 71.6 percent (Table 1). By region, there is considerable variation, with the coverage in South Asia being most comprehensive, at 98 percent, while for the Middle East and North Africa only 39 percent of the population is included in our results.

Our data are only for children under the age of 60 months, so results can be strictly interpreted only as being a portrait of health inequality among that cohort. While largely driven by data considerations, this is a meaningful focus, since most preventable morbidity and mortality occur in this under six year-old age group. Furthermore we know that there is a strong correlation between pre-school age malnutrition, and subsequent growth attainment. This reflects that there is little potential for catch-up growth after the age of three years. So, we would argue that our results are broadly representative of overall and long run health inequality in the population.

\section{Results}

In Table 2 we initially present the country specific levels of stunting, using the -2 $\mathrm{z}$-score as the cut-off point, in keeping with standard procedure. In addition, we show a ranking of countries from the least to the most healthy child populations. The table also includes transformed average height in centimeters, as well as the standard deviation, using girls of 24 months as the reference group. We can see that there is a large

\footnotetext{
${ }^{9}$ The project is funded by the U.S. Agency for International Development, and implemented by Macro International. See http://www.measuredhs.com

${ }^{10}$ See http://www.worldbank.org/lsms
} 
divergence in the levels of child health across countries. Sixty percent of the children in India are stunted, with its neighbor Bangladesh close behind at 57.5 percent. Likewise, the transformed average heights differ, as we would expect, by nearly eight centimeters between the United States reference population and Bangladesh.

Table 3 presents the results of our measures of health inequality. In the first column, the level of health inequality for each country, $I(k)$, is shown. There is considerable variation in the degree of intra-country inequality. Uzbekistan, Pakistan, Chad, and Nigeria have the highest levels, while intra-country inequality is lowest in Trinidad and Tobago, Thailand, and Sri Lanka. We also plot the relationship between inequality and the degree of stunting, both in terms of rankings and actual levels (Figures 1 and 2). There is a small group of countries with low levels of stunting, which also have relatively low levels of inequality. However, beyond that group, and for the great majority of countries, there is no discernable relationship between these two indicators. For example, Benin, Rwanda, and Tanzania all have nearly identical inequality parameters (1.49 to 1.5). However, the levels of stunting in these countries are: 29.9, 53.7, and 47.4 percent, respectively. Similarly, Nigeria and Yemen have the same level of stunting, but inequality parameters of 2.7 and 1.4, respectively. Thus, it is clear that countries with comparable levels of overall health status do not necessarily have the same level of health inequality, and vice versa. In a similar vein, we explore whether there is any relationship between levels of headcount poverty, based on purchasing power parity corrected, one dollar per day poverty lines, and levels of within-country health inequality. The plot in Figure 3 presents a similar story: other than the countries with very low poverty headcounts also having low inequality, there is no relationship.

The last column of Table 3 shows each country's contribution to between-country inequality, as well as the sum thereof. Overall, less than one quarter of the total world inequality in health is due to between-country differences. This is a surprising and noteworthy result that contrasts with the evidence on inter-country income inequality, which is dominated by between-country differences. Milanovic's (2000) Theil decomposition of world income inequality in 1999 and 1993 finds that between country differences explain three-quarters of world inequality, with only one-quarter of world inequality being the within country component. Firebaugh (forthcoming) reviews numerous studies that decompose world income inequality into between- and withincountry components. His review estimates between-country inequality contributes between 65 and 79 percent of total world income inequality. ${ }^{11}$

This difference between health and income inequality is relevant for policy makers interested in reducing worldwide inequality. If most variation in welfare is between-country, as it is for income, it makes sense to concentrate on reducing betweencountry differences in mean welfare with policies that affect the flow of resources from the richest to the poorest countries, such as international aid or debt relief. However, our findings that between-country differences contribute relatively little to world inequality

\footnotetext{
${ }^{11}$ Many of the studies reviewed rely on Theil decompositions, although, some use log variance and MLD decompositions. A number of studies use one or more of these approaches, and the results only differ slightly by decomposition method.
} 
focus attention on addressing within-country inequality. Here, the policies of interest are domestic, and most likely depend on a country's ability to deliver basic health care to all of its citizens.

Combined within-country inequality in China and India comprises nearly half of all world health inequality. This large contribution is simply a result of their combined populations representing over half of the share of countries in the analysis, coupled with the fact that the between-country contribution, as discussed above, is relatively small. In the case of China, however, the population share is more than 20 percent greater than China's contribution to world inequality; while in the case of India, the contribution of within-country inequality to the total is nearly identical to the share of the population. It is also interesting to note that like China, other countries that were part of the Soviet Union, as well as Vietnam, show a marked divergence between their contribution to within-country inequality and their population shares. Most pronounced is the case of Russia. Its contribution to world health inequality is less than one percent even though its share of the population in the analysis is 3.5 percent. Kazakhstan and the Kyrgyz Republic display similar patterns. Uzbekistan, in contrast, contributes more to world health inequality than its share of the world population would lead us to expect. This finding, however, is consistent with the high degree of within-country inequality, as shown in Table 2. Other countries with high inequality, such as Pakistan, display a similar pattern in terms of their country shares being less than their contribution to world health inequality.

\section{Discussion}

In this paper we have developed an innovative approach to measuring, and decomposing world health inequality. We are motivated by the underlying proposition that quantifying health inequality, like income inequality, is an important area of research. Health is a well-recognized measure of well-being, that arguably belongs in a social welfare function. To borrow Sen's terminology, poor health is an intrinsically important measure of capability deprivation. Thus, reducing inequality in health represents a practical and compelling policy objective.

Our use of standardized heights to measure inequality avoids the measurement pitfalls of more traditional measures of health such as morbidity, mortality, and life expectancy. It also avoids the measurement problems associated with using incomes across time or place to compare welfare. In addition, the long rightward tail of income distributions implies that inequality can be unduly influenced by the welfare of the rich, while most policy analysts care, rightly, about the poor. Because the height distribution does not have a rightward skew, measuring height inequality does not suffer this problem. If anything, the opposite is true.

Beyond methods, our calculation of world height inequality produces one provocative and unexpected result: within-country variation is the source of most inequality, rather than the differences between countries. Why do our results on health inequality differ so dramatically from income inequality? The answer is likely to be 
found in the fact that the relationship between income and health, particularly when measured by nutrition indicators, is a strongly concave function. As incomes improve from low levels, the associated improvements in health taper off quickly, so that stunting worldwide will be found among poor people in poor countries. Even modest improvements in a country's welfare can compress its height distribution significantly, precisely because height has genetic upper bounds while income does not.

This explanation, of course, begs the question of whether examining world inequality using health or income is more relevant and informative. Like the analogous question of whether it is preferred to define poverty using money metrics or the deprivation of capabilities such as poor health, there is no right answer; it depends on the question at hand. But what is amply clear is that unlike world income inequality, world health inequality is primarily a within-country phenomenon. This suggests that the most effective way to reduce world health inequality is to focus on within-country inequality, especially in the poorest countries. 


\section{References}

Brockerhoff, M., Hewett, P. 2000. Inequality of child mortality among ethnic groups in sub-Saharan Africa. Bulletin of the World Health Organization 78, 30-41.

Carr, H. R. 1988. Time trends in inequalities in health. Journal of Biosocial Science. 20, 265-273.

Deaton, A.. 1999. Inequalities in Income and Inequalities in Health. NBER Working Paper 7141.

Deaton, A. 2001. Relative Deprivation, Inequality and Mortality. NBER Working Paper 8099.

Firebaugh, G. Forthcoming. Five propositions about world income inequality. In New Geography of Global Income Inequality, draft.

Gakidou, E. E., Murray, C. J. L., Frenk, J. 2000. Defining and measuring health inequality: An approach based on the distribution of health expectancy. Bulletin of the World Health Organization 78 (1), 42-54.

Gwatkin, D. R. 2000. Health inequalities and the health of the poor: What do we know? What can we do? Bulletin of the World Health Organization 78(1), 3-18.

Gwatkin, D.R. 2000. Poverty and inequalities in health within developing countries: filling the information gap. Leon, D.A., and Walt., G. (Eds.) in Poverty, Inequality, and Health: An International Perspective. Oxford University Press, Oxford, 2001.

Haddad, L., Hoddinott, J., Alderman, H., eds. 1997. Intrahousehold Resource Allocation in Developing Countries: Methods, Models, and Policy. Johns Hopkins University Press, Baltimore, MD.

Haughton, D. 1997 Explaining Child Nutrition in Vietnam. Economic Development and Cultural Change 45 (3), 541-546.

Mackenbach, J. P., Kunst, A. E. 1997. Measuring the magnitude of socioeconomic inequalities in health: An overview of available measures illustrated with two examples from Europe. Social Science and Medicine 44, 757-771.

Milanovic, B. 2000. True world income distribution, 1988 and 1993: First calculations based on household surveys alone. Mimeo, World Bank.

Murray, C. J. L., Gakidou, E. E., Frenk, J. 1999. Health inequalities and social group differences: What should we measure? Bulletin of the World Health Organization 77 (2), 537-543. 
Pradhan, M. 2000. How many questions should be in a consumption questionnaire? Evidence from a repeated experiment in Indonesia. Cornell Food and Nutrition Program Working Paper No. 112. Ithaca, NY.

Sahn, D. E., Alderman, H. 1997. On the determinants of nutrition in Mozambique: The importance of age-specific effects. World Development 25 (4), 577-588.

Sahn, D. E., Younger, S. 2000. Expenditure incidence in Africa: Microeconomic evidence. Fiscal Studies 21(3), 329-347.

Scott, C., Amenuvegbe, B. 1990. Effect of recall duration on reporting of household expenditures: An experimental study in Ghana. Social Dimensions of Adjustment in Sub-Saharan Africa Working Paper 6, Washington DC: World Bank.

Sen, A. 1979. Personal utilities and public judgment: Or what's wrong with welfare economics?" Economic Journal 89 (355), 537-558.

Sen, A. 1987. The Standard of Living: Lecture II, Lives and capabilities, in: Hawthorn, G. (Ed.), The Standard of Living. Cambridge University Press, Cambridge, pp. 20-38.

Sen, A. 1985. Commodities and Capabilities. North Holland, Amsterdam.

Skoufias, E. 1998. Determinants of child health during the economic transition in Romania.” World Development 26 (11), 2045-2056.

Thomas, D., Lavy, V., Strauss, J. 1996. Public policy and anthropometric outcomes in the Cote D'Ivoire. Journal of Public Economics 61 (2), 155-192.

van Doorslaer, E. et al. 1997. Income-related inequalities in health: Some international comparisons. Journal of Health Economics 16, 93-112.

Wagstaff, A., Paci P., van Doorslaer, E. 1991. On the measurement of inequalities in health. Social Science and Medicine 33, 545-557.

Whitehead, M. 2000. The Concepts and Principles of Equity and Health. Programme on Health Policies discussion paper, World Health Organization Regional Office for Europe, Copenhagen.

Wilkinson, R. G.1996. Unhealthy Societies, The Afflictions of Inequality. Routledge, London.

Wilkinson, R. G. 1997. Socioeconomic determinants of health: Health inequalities: Relative or absolute material standards?" British Medical Journal 314, 591-595. 
World Health Organization. 1986. Social Justice and Equity in Health. Report on a WHO Meeting (Leeds, United Kingdom, 1985), Regional Office for Europe. (ICP/HSR 804/m02), Copenhagen.

World Health Organization. 1983. Measuring Change in Nutritional Status: Guidelines for Assessing the Nutritional Impact of Supplementary Feeding Programmes for Vulnerable Groups. WHO, Geneva.

World Health Organization Regional Office for Europe. 1985. Targets for Health For All. European Health for All Series No. 1, WHO. 
Table 1

Coverage of datasets

\begin{tabular}{lcr}
\hline & $\begin{array}{l}\text { Percentage } \\
\text { population } \\
\text { covered }\end{array}$ & \multicolumn{2}{c}{$\begin{array}{l}\text { Percentage of } \\
\text { world } \\
\text { population }\end{array}$} \\
\hline Region & 79.9 & 33.7 \\
Eurt Asia \& Pacific & 32.1 & 14.7 \\
Latin America \& Caribbean & 57.7 & 8.5 \\
Middle East \& North Africa & 38.7 & 5.1 \\
South Asia & 98.0 & 22.2 \\
Sub-Saharan Africa & 62.5 & 10.7 \\
North America & 89.9 & 5.1 \\
World & 71.6 & 100.0 \\
\hline
\end{tabular}


Table 2

Country data on heights and prevalence of stunting (girls of 24 months taken as reference group)

\begin{tabular}{|c|c|c|c|c|c|c|c|c|}
\hline Name & $\begin{array}{l}\text { Avg. } \\
\text { Height }(\mathrm{cm})\end{array}$ & $\begin{array}{l}\text { Standard } \\
\text { deviation }\end{array}$ & $\% \mathrm{HAZ}<-2$ & $\begin{array}{l}\text { Rank } \\
\text { stunting }\end{array}$ & $\begin{array}{l}\text { Rank } \\
\text { inequality }\end{array}$ & $\begin{array}{l}\text { Avg. } \\
\text { transformed } \\
\text { height }(\mathrm{cm})\end{array}$ & $\begin{array}{l}\text { Standard } \\
\text { deviation }\end{array}$ & $\begin{array}{l}\text { Headcount } \\
\text { (PPP US\$1/day) }\end{array}$ \\
\hline Bangladesh & 79.93 & 12.72 & 57.52 & 49 & 38 & 75.00 & 5.06 & 29.10 \\
\hline Benin & 73.58 & 10.01 & 29.94 & 21 & 25 & 78.53 & 4.88 & \\
\hline Bolivia & 75.05 & 9.93 & 30.12 & 22 & 24 & 78.30 & 4.84 & 11.30 \\
\hline Brazil & 86.19 & 14.77 & 11.88 & 4 & 8 & 80.79 & 4.33 & 5.10 \\
\hline Burkina Faso & 80.79 & 13.31 & 35.67 & 29 & 36 & 77.83 & 5.16 & 61.20 \\
\hline Burundi & 74.75 & 8.82 & 48.32 & 42 & 30 & 76.20 & 4.85 & \\
\hline Cameroon & 80.94 & 13.75 & 28.93 & 20 & 15 & 78.16 & 4.64 & \\
\hline Central African Republic & 73.37 & 9.76 & 36.49 & 31 & 37 & 77.49 & 5.18 & 66.60 \\
\hline Chad & 80.35 & 13.50 & 42.46 & 36 & 48 & 77.06 & 5.97 & \\
\hline China & 90.11 & 12.72 & 26.00 & 12 & 41 & 78.56 & 5.43 & 18.50 \\
\hline Colombia & 84.53 & 13.61 & 17.60 & 6 & 4 & 79.20 & 3.78 & 11.00 \\
\hline Comoros & 73.21 & 10.02 & 36.59 & 32 & 32 & 77.50 & 4.98 & \\
\hline Cote d'Ivoire & 74.27 & 10.19 & 27.91 & 17 & 20 & 78.40 & 4.79 & 12.30 \\
\hline Dominican Republic & 83.97 & 14.21 & 18.10 & 7 & 7 & 79.36 & 4.22 & 3.20 \\
\hline Egypt, Arab Rep. & 84.99 & 14.30 & 27.51 & 16 & 40 & 78.71 & 5.39 & 3.10 \\
\hline Ghana & 74.21 & 9.81 & 28.66 & 19 & 29 & 78.35 & 4.90 & \\
\hline Guatemala & 80.02 & 13.01 & 52.56 & 44 & 34 & 75.53 & 4.86 & 39.80 \\
\hline Haiti & 82.12 & 13.53 & 33.91 & 27 & 39 & 77.64 & 5.27 & \\
\hline India & 75.02 & 11.02 & 60.03 & 50 & 46 & 74.59 & 5.60 & 44.20 \\
\hline Indonesia & 82.39 & 12.99 & 43.53 & 38 & 43 & 76.94 & 5.47 & 15.20 \\
\hline Kazakhstan & 76.68 & 10.34 & 15.97 & 5 & 9 & 80.17 & 4.45 & 1.50 \\
\hline Kenya & 82.60 & 13.25 & 36.19 & 30 & 31 & 77.44 & 4.93 & 26.50 \\
\hline Madagascar & 78.09 & 12.71 & 57.49 & 48 & 23 & 75.09 & 4.63 & 60.20 \\
\hline Malawi & 78.71 & 13.01 & 52.62 & 45 & 35 & 75.59 & 4.99 & \\
\hline Mali & 73.04 & 9.95 & 33.79 & 26 & 45 & 78.00 & 5.61 & 72.80 \\
\hline Morocco & 83.06 & 13.60 & 31.48 & 23 & 26 & 77.93 & 4.85 & 1.00 \\
\hline
\end{tabular}


Table 2 continued

Country data on heights and prevalence of stunting (girls of 24 months taken as reference group)

\begin{tabular}{|c|c|c|c|c|c|c|c|c|}
\hline Name & $\begin{array}{l}\text { Avg. } \\
\text { Height }(\mathrm{cm})\end{array}$ & $\begin{array}{l}\text { Standard } \\
\text { deviation }\end{array}$ & $\% \mathrm{HAZ}<-2$ & $\begin{array}{l}\text { Rank } \\
\text { stunting }\end{array}$ & $\begin{array}{l}\text { Rank } \\
\text { inequality }\end{array}$ & $\begin{array}{l}\text { Avg. } \\
\text { transformed } \\
\text { height }(\mathrm{cm})\end{array}$ & $\begin{array}{l}\text { Standard } \\
\text { deviation }\end{array}$ & $\begin{array}{l}\text { Headcount } \\
\text { (PPP US } \$ 1 / \text { day) }\end{array}$ \\
\hline Mozambique & 72.27 & 10.17 & 39.60 & 33 & 42 & 77.28 & 5.38 & 37.90 \\
\hline Namibia & 79.90 & 14.19 & 31.65 & 24 & 17 & 77.98 & 4.70 & 34.90 \\
\hline Nepal & 72.29 & 9.20 & 52.82 & 46 & 12 & 75.62 & 4.44 & 37.70 \\
\hline Nicaragua & 83.86 & 13.69 & 28.66 & 18 & 16 & 78.15 & 4.66 & \\
\hline Niger & 78.25 & 13.61 & 42.25 & 35 & 44 & 76.82 & 5.47 & 61.40 \\
\hline Nigeria & 79.47 & 13.28 & 45.67 & 39 & 47 & 76.48 & 5.78 & 70.20 \\
\hline Pakistan & 79.04 & 12.86 & 52.30 & 43 & 49 & 75.47 & 6.05 & 31.00 \\
\hline Peru & 83.06 & 13.38 & 34.56 & 28 & 13 & 77.66 & 4.60 & 15.50 \\
\hline Russian Federation & 136.02 & 16.20 & 10.39 & 3 & 6 & 80.88 & 4.11 & 7.10 \\
\hline Rwanda & 80.21 & 12.51 & 53.71 & 47 & 27 & 75.69 & 4.77 & 35.70 \\
\hline Senegal & 81.40 & 13.82 & 26.93 & 14 & 21 & 78.49 & 4.79 & 26.30 \\
\hline Sri Lanka & 76.99 & 8.72 & 27.47 & 15 & 5 & 77.95 & 3.93 & 6.60 \\
\hline Tanzania & 79.49 & 13.23 & 47.42 & 41 & 28 & 76.25 & 4.77 & 19.90 \\
\hline Thailand & 77.51 & 8.79 & 22.05 & 10 & 3 & 78.54 & 3.53 & 1.00 \\
\hline Togo & 74.26 & 10.17 & 26.12 & 13 & 14 & 78.74 & 4.69 & \\
\hline Trinidad and Tobago & 80.82 & 10.07 & 4.64 & 2 & 2 & 81.57 & 3.54 & \\
\hline Tunisia & 78.00 & 9.53 & 18.14 & 8 & 11 & 79.72 & 4.64 & 1.00 \\
\hline Turkey & 84.17 & 13.77 & 21.83 & 9 & 18 & 79.32 & 4.76 & 2.40 \\
\hline Uganda & 76.60 & 11.41 & 41.20 & 34 & 33 & 76.85 & 4.96 & 36.70 \\
\hline United States & & 0.00 & 2.10 & 1 & 1 & 82.63 & 3.27 & \\
\hline Uzbekistan & 76.00 & 11.08 & 32.74 & 25 & 50 & 78.50 & 6.52 & 3.30 \\
\hline Yemen, Rep. & 77.50 & 13.09 & 46.13 & 40 & 22 & 76.84 & 4.77 & 5.10 \\
\hline Zambia & 79.70 & 13.33 & 43.30 & 37 & 19 & 76.57 & 4.65 & 72.60 \\
\hline Zimbabwe & 74.76 & 10.34 & 24.88 & 11 & 10 & 78.81 & 4.47 & 36.00 \\
\hline Total & 84.44 & 17.38 & 35.77 & & & 77.60 & 5.70 & \\
\hline
\end{tabular}


Table 3

Decomposition of inequality (girls of 20 months taken as reference group)

\begin{tabular}{|c|c|c|c|}
\hline Name & $\begin{array}{l}\text { Inequality } \\
I^{*}(k)\end{array}$ & $\begin{array}{l}\text { Contribution to } \\
\text { world } \\
\text { inequality (\%) }\end{array}$ & $\begin{array}{l}\text { Average height } \\
\text { in centimeters }\end{array}$ \\
\hline Bangladesh & 1.91 & 2.35 & 75.0 \\
\hline Benin & 1.49 & 0.09 & 78.5 \\
\hline Bolivia & 1.45 & 0.11 & 78.3 \\
\hline Brazil & 0.84 & 1.37 & 80.8 \\
\hline Burkina Faso & 1.82 & 0.19 & 77.8 \\
\hline Burundi & 1.57 & 0.10 & 76.2 \\
\hline Cameroon & 1.27 & 0.18 & 78.2 \\
\hline Central African Republic & 1.88 & 0.06 & 77.5 \\
\hline Chad & 2.85 & 0.20 & 77.1 \\
\hline China & 2.07 & 25.15 & 78.6 \\
\hline Colombia & 0.47 & 0.19 & 79.2 \\
\hline Comoros & 1.66 & 0.01 & 77.5 \\
\hline Cote d'Ivoire & 1.40 & 0.20 & 78.4 \\
\hline Dominican Republic & 0.83 & 0.07 & 79.4 \\
\hline Egypt, Arab Rep. & 2.00 & 1.20 & 78.7 \\
\hline Ghana & 1.54 & 0.28 & 78.3 \\
\hline Guatemala & 1.67 & 0.18 & 75.5 \\
\hline Haiti & 2.00 & 0.15 & 77.6 \\
\hline India & 2.61 & 25.12 & 74.6 \\
\hline Indonesia & 2.20 & 4.40 & 76.9 \\
\hline Kazakhstan & 0.97 & 0.15 & 80.2 \\
\hline Kenya & 1.58 & 0.45 & 77.4 \\
\hline Madagascar & 1.43 & 0.21 & 75.1 \\
\hline Malawi & 1.80 & 0.19 & 75.6 \\
\hline Mali & 2.35 & 0.24 & 78.0 \\
\hline Morocco & 1.49 & 0.41 & 77.9 \\
\hline Mozambique & 2.11 & 0.35 & 77.3 \\
\hline Namibia & 1.31 & 0.02 & 78.0 \\
\hline Nepal & 1.22 & 0.27 & 75.6 \\
\hline Nicaragua & 1.30 & 0.06 & 78.2 \\
\hline Niger & 2.26 & 0.22 & 76.8 \\
\hline Nigeria & 2.67 & 3.16 & 76.5 \\
\hline Pakistan & 3.12 & 4.03 & 75.5 \\
\hline Peru & 1.25 & 0.30 & 77.7 \\
\hline Russian Federation & 0.71 & 1.02 & 80.9 \\
\hline Rwanda & 1.50 & 0.12 & 75.7 \\
\hline Senegal & 1.41 & 0.12 & 78.5 \\
\hline Sri Lanka & 0.65 & 0.12 & 78.0 \\
\hline Tanzania & 1.50 & 0.47 & 76.3 \\
\hline Thailand & 0.29 & 0.17 & 78.5 \\
\hline Togo & 1.26 & 0.06 & 78.7 \\
\hline Trinidad and Tobago & 0.20 & 0.00 & 81.6 \\
\hline Tunisia & 1.17 & 0.11 & 79.7 \\
\hline
\end{tabular}


Table 3 continued

Decomposition of inequality (girls of 20 months taken as reference group)

\begin{tabular}{|c|c|c|c|}
\hline Name & $\begin{array}{l}\text { Inequality } \\
I^{*}(k)\end{array}$ & $\begin{array}{l}\text { Contribution to } \\
\text { world } \\
\text { inequality }(\%)\end{array}$ & $\begin{array}{l}\text { Average height } \\
\text { in centimeters }\end{array}$ \\
\hline Turkey & 1.34 & 0.83 & 79.3 \\
\hline Uganda & 1.67 & 0.34 & 76.8 \\
\hline United States & 0.00 & 0.00 & 82.6 \\
\hline Uzbekistan & 3.39 & 0.80 & 78.5 \\
\hline Yemen, Rep. & 1.42 & 0.23 & 76.8 \\
\hline Zambia & 1.36 & 0.13 & 76.6 \\
\hline Zimbabwe & 1.05 & 0.12 & 78.8 \\
\hline Between-country & & 23.68 & \\
\hline All countries above & 2.496892 & 100.00 & 77.6 \\
\hline
\end{tabular}




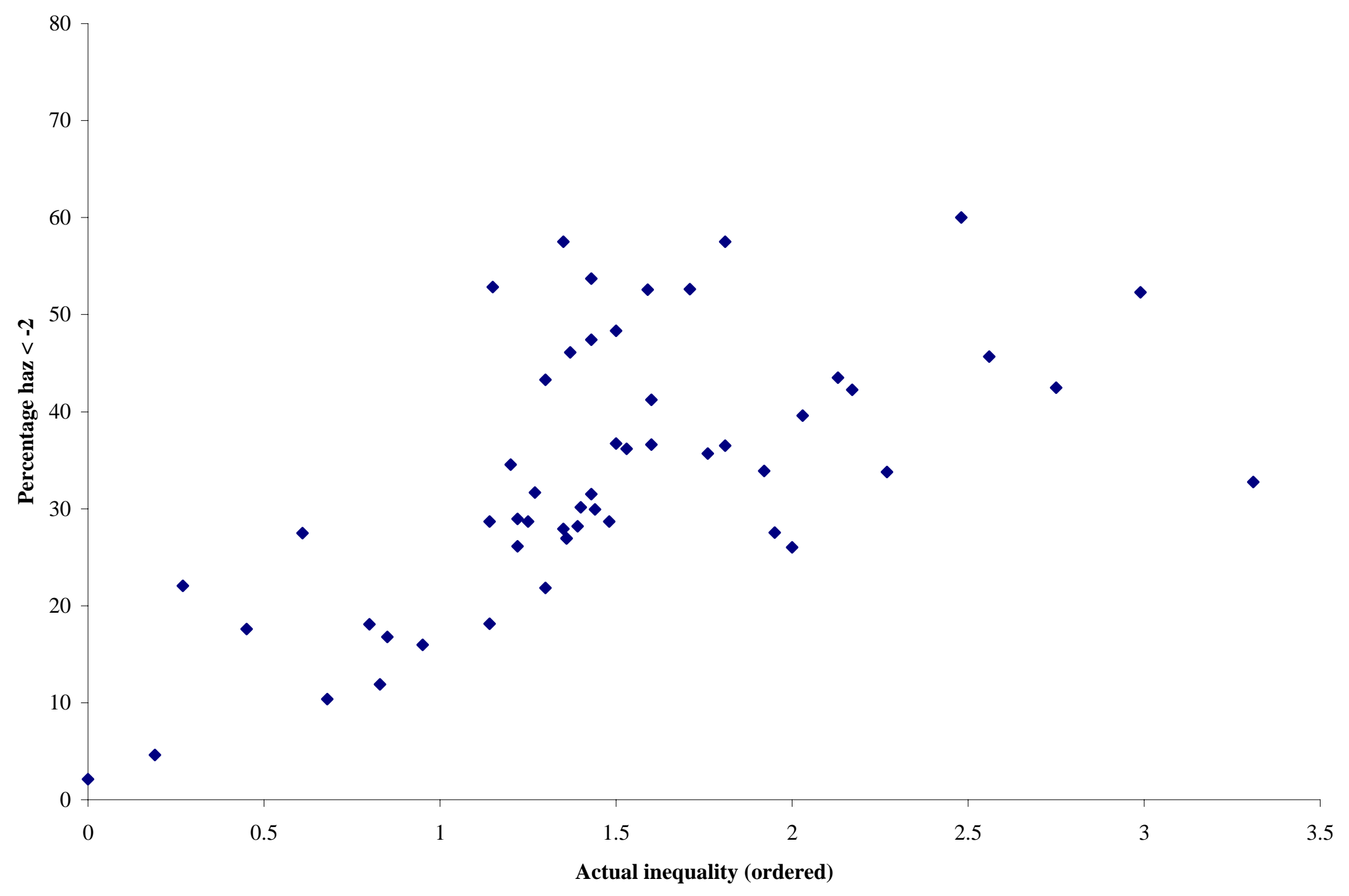

Fig. 1. Graph of stunting against actual inequality 


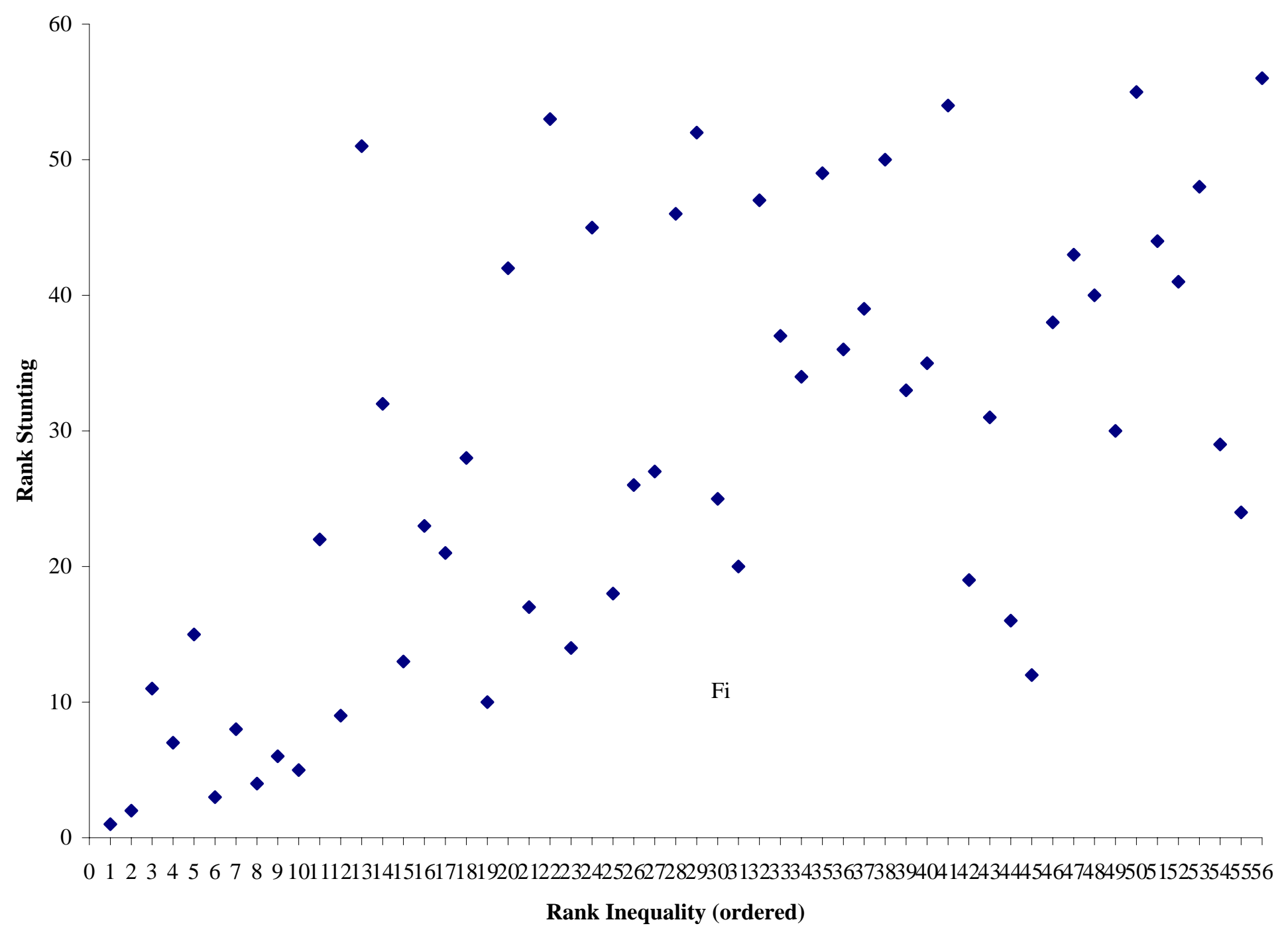

Fig. 2. Graph of rank stunting against rank inequality 


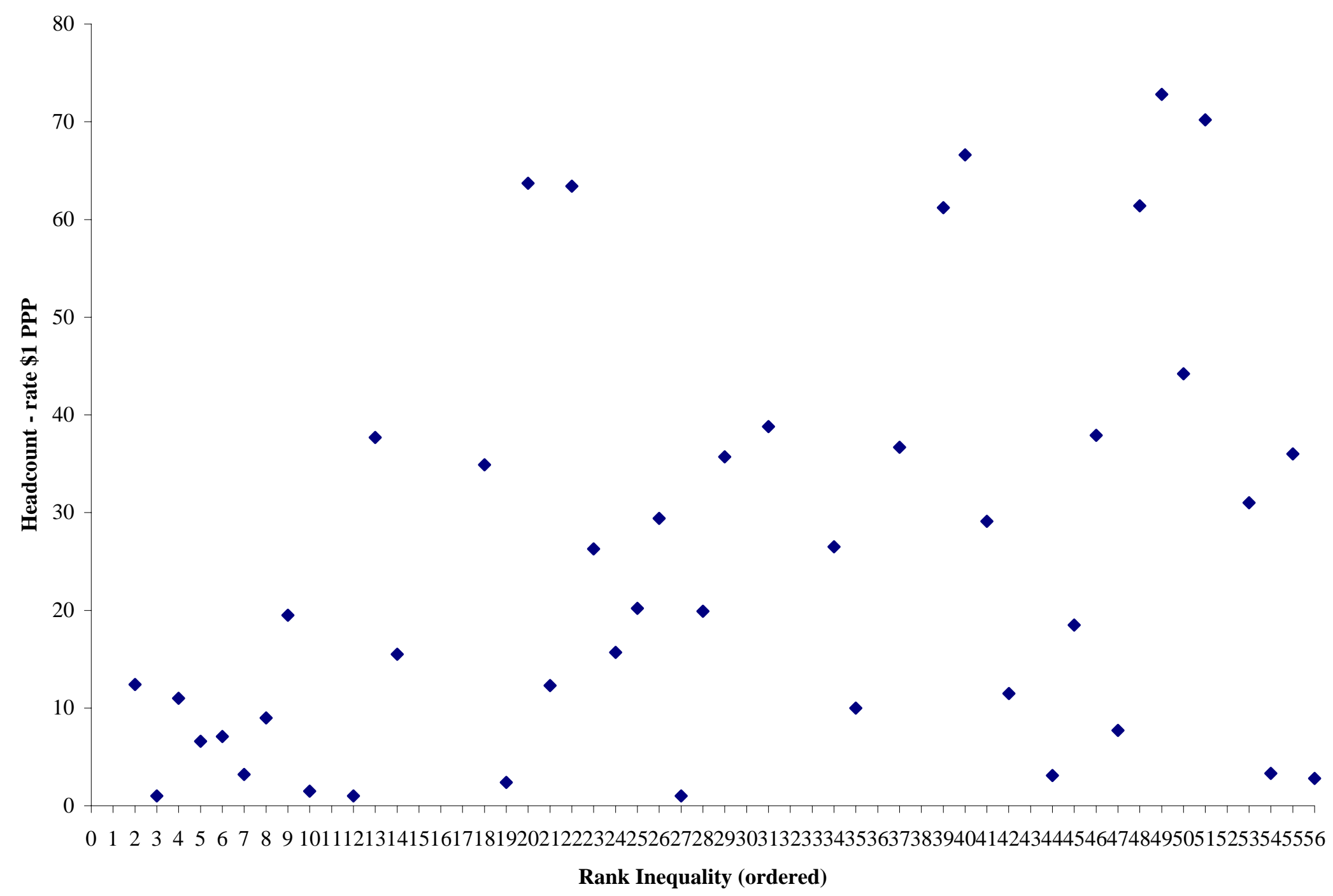

Fig. 3. Graph of headcount against rank inequality 